EPiC Series in Built Environment
Volume 1, 2020, Pages 454-462
Associated Schools of Construction Proceed-
ings of the 56th Annual International Conference

\title{
The Relationship of Embodied Energy and Cost of Buildings and Building Materials
}

\author{
Manish K. Dixit, Ph.D., Sarel Lavy, Ph.D., and Parag Abdagiri, M.S. \\ Texas A\&M University \\ College Station, TX
}

\begin{abstract}
Buildings consume nearly half of global energy each year in their construction and operation as embodied and operational energy releasing approximately $40 \%$ of global carbon emission. Embodied energy (EE) is consumed indirectly through the use of construction materials, assemblies, and equipment, and directly in construction processes and related transportation. Operational energy $(\mathrm{OE})$ is consumed in building air-conditioning, heating, lighting, and powering equipment. Both $\mathrm{EE}$ and $\mathrm{OE}$ must be minimized to lower this huge energy footprint of buildings. To decrease EE, a complete and accurate EE assessment is essential, which, however, is a quite data-intensive and time-consuming process. EE is conventionally computed using process- and input-output (IO)-based methods. Hybrid approaches that combine the two methods are also used to compute EE. In an IO-based method, macroeconomic data is translated into energy flows, which indicates a potential relationship between energy and economic flows, and consequently between EE and cost. In this paper, we investigated the EE-cost relationship at the building and construction material levels and found a strong positive correlation between the EE and cost of the study buildings. The results indicate a need to further analyze this relationship through regression analysis to see if EE can be predicted from cost data.
\end{abstract}

Key Words: Embodied energy, cost, construction materials, life cycle energy, embodied carbon

\section{Introduction}

The sum of energy consumed by a building over its service life includes embodied and operational energy (Dixit, 2017a; Stephan \& Stephan, 2016). Embodied energy (EE) is consumed indirectly through all materials, assemblies, and equipment installed in a building, each of which uses significant energy during its production and delivery to a construction site. EE is also spent directly through construction, fabrication, transportation, consultancy, and administration processes, which consume electricity, natural gas, and a variety of petroleum products (Dixit et al., 2015; Balouktsi \& Lützkendorf, 2016). Operational energy (OE) is used for building air-conditioning, heating and lighting including operating building equipment. The direct and indirect energy embodied in a building's initial construction is termed its initial embodied energy (IEE) (Crawford, 2004; Langston, 2006). When occupied, the building undergoes the activities of repair, maintenance, replacement, and 
retrofit, each consuming materials and processes with EE. The sum of their EE is known as recurrent embodied energy (REE) (Vukotic et al., 2010; Dixit, 2018). When the service life of the building ends, the total energy used in its demolition, material disposal, transportation, reuse and recycling is called demolition energy (DE) (Crawford, 2004). These life cycle energy components of IEE, REE, and DE indicate that the type and quantity of construction materials and methods impact a building's energy and environmental footprint.

Measuring and minimizing embodied energy is more challenging and data-intensive than operational energy because required data is either not available or available with poor quality and representativeness (Ristimaki et al., 2013; Balouktsi \& Lützkendorf, 2016). The processes of data collection, treatment, and EE calculation requires considerable time. Despite profound research on $\mathrm{EE}$, there is no consensus on a standard and globally-accepted approach to completely and reliably measure EE, which makes EE assessment further challenging (Dixit et al., 2015; Ristimaki et al., 2013). There are three methods commonly applied to compute EE: (1) process-based; (2) inputoutput-based (IO-based); and (3) hybrid methods. Each of the methods has limitations. For instance, the results of process-based methods are regarded more accurate and reliable than IO-based methods because they are based on actual process data collected from manufacturers and construction sites (Dixit, 2017a). However, since actual data is not available for all processes, process-based calculations are not considered complete due to the lack of process data resulting in a truncation of system boundary (Crawford, 2004). A system boundary defines which inputs are included in an EE calculation. IO-based methods utilize macroeconomic data and cover a complete system but their results are considered unreliable due the use of uncertain energy prices (Crawford, 2004; Stephan \& Stephan, 2016). Hybrid methods combine the advantages of the two methods to cover a wider system boundary with improved reliability (Crawford, 2004). In an IO-based method, monetary flows between industry sectors are converted into physical and energy flows using product or energy prices (Dixit, 2018). This means that each monetary transaction has embedded energy and carbon footprint, which can possibly be utilized to predict embodied energy (Carter et al., 1981; Dixit, 2018). This study focuses on examining if there is any correlation between the EE and cost of a building at the building and construction material levels. If a significant correlation is found between EE and these costs, EE may be predicted from cost data by conducting further regression analysis on multiple case studies. The type and strength of the relationship of EE and cost would also help clarify if lowering energy and environmental footprint could increase a project's cost.

\section{Literature Review: Embodied Energy and Cost Relationship}

Several studies have emphasized the issues with EE data availability and quality, which impede the industry-wide application of embodied energy analyses. Several countries, e.g., India, do not have a place-based EE database, which can be applied for life cycle EE analysis. In places where EE data is available, the data lacks reliability, consistency, and representativeness in terms of time and geographic location (Dixit, 2017a). Computing, verifying, and establishing EE database consumes significant time and resources (Langston, 2006). Once established, it needs to be updated constantly, which further requires resources (Dixit, 2018). Because IO-based approaches utilize macroeconomic data to compute EE, studies also investigated the relationship of the cost and EE of a building. The purpose was to examine if cost data can predict the energy embodied in a building and its constituent materials. If so, the resource-consuming process of $\mathrm{EE}$ data calculation can be circumvented, and $\mathrm{EE}$ analysis can be performed using cost data. The correlation of EE and cost is found by multiple studies to be strong and positive. However, the correlation weakens when analysis is performed at the construction material level. 
Among the key early studies was by Costanza (1980), who realized the EE-cost relationship and investigated the link between energy and economic flows. This study used the national economic system with household and government sector endogenous to the intermediate flows matrix, thereby including the energy embodied in labor and government activities in the system boundary. The results showed that the energy embodied in a product was strongly correlated to the economic output of its production sector. Later, Ding (2004) studied 20 public high schools in Australia to examine the correlation of life cycle cost and energy use and resulting environmental impacts. The results showed that nearly $70 \%$ of variation in life cycle energy use and 58\% in resulting environmental impacts can be explained by life cycle cost variations, which further underscored a stronger and positive correlation between EE and cost. Likewise, Langston (2006) hypothesized that a building's initial capital and recurrent operating and maintenance costs are positively correlated to its initial embodied (IEE) and recurrent embodied energy (REE). Using EE data from Treloar (1998) and cost data from the bills of quantities of the study buildings, the correlation of energy and cost was analyzed. Although findings indicated a strong and positive correlation between the life cycle cost and EE components at the building level, correlation weakened at the material level. In another study, Jiao et al (2012) computed the life cycle EE and cost components of two commercial buildings in China and one energy-efficient building in New Zealand to study EE-cost correlation. This study utilized published EE data and also included the energy embodied in labor, which was conventionally overlooked. A very strong positive correlation was indicated between the total life cycle EE and cost of the study buildings ( $r^{2}=0.93$ and 0.99 ). The correlation between the EE and cost of individual building elements was positive and linear for the Chinese case studies. This correlation at the building element level was weaker for the New Zealand building. Copiello (2016) utilized the Inventory of Carbon and Energy data (Hammond et al., 2011) to test the correlation between EE and cost of building materials. Although a positive correlation was found, it was a non-linear one indicating it may change in the future. This study concluded that further research is needed to substantiate EE-cost relationship. In a recent study, Dixit (2017b) applied input-output-based hybrid (IOH) data to analyze the relationship of EE and cost of 21 construction materials. The studied commodities of their IOH model were disaggregated for specificity and the model included the energy embodied in labor as well as capital investments. Four cases were analyzed that utilized: (1) IO-based data; (2) IOH data; (3) $\mathrm{IOH}$ data with labor and capital inputs; and (4) IOH data with commodities disaggregated. In all cases, the correlation of EE and cost of the materials was found to be very strong and positive $\left(r^{2}=\right.$ 0.86-0.98). This study recommended further investigation at the level of building component groups.

\section{Research Goal and Methods}

The current state of literature clearly indicates a need to further study the relationship of EE and cost. The main goal of this paper is to conduct case study-based research to investigate the correlation of the EE and cost of five academic buildings constructed between 2009 and 2013 at Texas A\&M University's Main Campus. The cost data for the buildings were collected from the university's architect office, which included building material, labor, and equipment costs categorized by the divisions of the Master Format. Materials such as terrazzo flooring, ceramic tiles, and face brick were clustered, as the manufacturing industry sector producing these materials was assumed common.

Similarly, membrane, damp-proofing and waterproofing materials were clustered for similar reasons. Because the cost data was given in US dollars and needed to be converted into mass units (kg), Year specific RS Means Building Construction Cost data was used to convert all materials to mass units. The EE data were sourced from the IOH model developed by Dixit \& Singh (2018). The model included the energy embodied in human labor and capital inputs. This model offers EE intensities in physical units (MBtu/\$) and circumvents the use of unreliable energy prices, which enhances the reliability of EE calculations. The EE intensities were provided for the five energy providing sectors of the United States' economy: (1) coal mining; (2) oil and gas extraction; (3) natural gas distribution; 
(4) electric power generation, transmission, and distribution; and (5) petroleum refineries. Energy source-specific Primary Energy Factors (PEFs) were sourced and used from Dixit et al. (2014). The PEFs are applied to convert secondary or site energy sources such as electricity and gasoline into primary or source energy. These PEFs account for energy conversion efficiency including energy lost or used in the processes of energy extraction, processing/generation and distribution.

To measure the magnitude of correlation, the coefficients of determination $\left(r^{2}\right)$ were calculated and interpreted as $0-0.09$ (weak), $0.09-0.64$ (strong moderate), $0.64-0.81$ (strong), and $0.81-1.0$ (very strong) (Chan, 2003; Taylor, 1990). In addition, regression analysis was performed to compute slope gradient, $p$-value, and $t$-statistic. The EE of the buildings was computed in two ways: (1) using total aggregated cost of the buildings and utilizing the EE intensity of the aggregated construction sector; and (2) disaggregating total cost by major material groups and using material-specific EE intensities. This was done to examine if the cost disaggregation causes any significant variation in EE calculations.

\section{Findings}

Table 1 lists the EE values of the five buildings calculated with aggregated and disaggregated building costs, which shows a massive increase in EE (165-260\%) caused by disaggregation of the total cost. Approximately $60 \%, 52 \%, 71 \%, 60 \%$, and $45 \%$ of the total costs can be attributed to the disaggregated material groups in buildings "A" through " $\mathrm{E}$ ", respectively. These results underscore the significance of disaggregating building cost by major material groups and using material-specific IOH-based EE values to compute the $\mathrm{EE}$ of the whole building. The EE intensities per unit of gross floor area of buildings " $A$ " through "E" are $26 \mathrm{MBtu} / \mathrm{m}^{2}, 43 \mathrm{MBtu} / \mathrm{m}^{2}, 46 \mathrm{MBtu} / \mathrm{m}^{2}, 41 \mathrm{MBtu} / \mathrm{m}^{2}$, and $28 \mathrm{MBtu} / \mathrm{m}^{2}$, respectively. Figure 1 illustrates the strong correlation of the total EE of the five buildings after cost disaggregation with that of their total cost.

Table 1

EE of study buildings before and after disaggregation

\begin{tabular}{cccc}
\hline Building & $\begin{array}{c}\text { EE without disaggregation into } \\
\text { material costs (MBTU) (a) }\end{array}$ & $\begin{array}{c}\text { EE after disaggregation into } \\
\text { material costs (MBTU) (b) }\end{array}$ & $\begin{array}{c}\text { \% increase } \\
\text { [From (a) to (b)] }\end{array}$ \\
\hline A & 125,131 & 272,309 & 217.6 \\
B & 408,327 & 812,676 & 199.0 \\
C & 211,761 & 526,407 & 248.6 \\
D & 382,566 & 992,814 & 259.5 \\
E & 449,042 & 739,951 & 164.8 \\
\hline
\end{tabular}

Table 2 reports EE per unit of mass of major material groups for the five study buildings. Materials such as concrete, $\mathrm{CMU}$, and aluminum represent fairly consistent $\mathrm{EE}$ across the buildings, whereas material groups containing multiple material types such as "Membrane/Waterproofing and Sealants" and "Terrazzo Flooring/Ceramic Tile/Face Brick" show higher variation in their EE. The left-side scatter plot in Figure 2 shows the correlation between total EE (MBtu) and total cost (\$) of different material groups for the five buildings. The right-side plot illustrates the correlation for all material groups of all five buildings. The coefficient of determination $\left(r^{2}\right)$ for all five building ranges between 0.57 and 0.86 , which indicates a strong to very strong positive correlation between the total $\mathrm{EE}$ and the cost of the material groups. Figure 3 shows the correlation of EE and cost of material groups per unit of mass. Both the left- and right-side scatter plots show very strong positive correlation between 
EE (MBtu/ $\left.\mathrm{m}^{2}\right)$ and cost $\left(\$ / \mathrm{m}^{2}\right)$ of material groups for the five buildings individually (left-side) and collectively (right-side) with the values of $r^{2}$ to be nearly 1.00 .

Because results showed a strong to very strong positive correlation, we conducted simple linear regression analyses to examine if EE can be predicted from cost data. The results of these regression analyses showed a range of extremely small Significance of $F$ (1.906E-10 to 8.415E-69), indicating it is extremely less likely that the shown correlation is random. The smaller $p$-values $(0.00126$ to $3.30 \mathrm{E}-$ 94) further substantiated the confidence of the demonstrated EE-cost correlation at the material group levels. The slope coefficient for total EE-cost correlation was 0.0136 which would help estimate embodied energy (dependent variable) from cost of building materials (independent variable). The equation of regressed line was $y=0.0136 x+8220.4$. The slope coefficient for EE-cost correlation per unit of material mass was 0.0235 with the equation of regressed line as $y=0.0235 x+0.0499$. Note that these equations are for all building material groups across the five educational buildings.

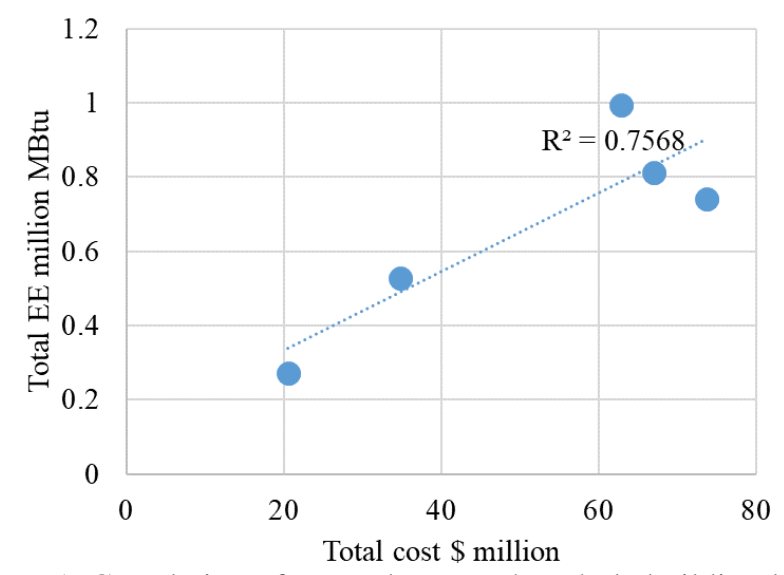

Figure 1. Correlation of EE and cost at the whole building level

Table 2

EE of material groups per unit of mass for the five buildings

\begin{tabular}{lccccc}
\hline & \multicolumn{5}{c}{ EE of Study } \\
\hline Major Material Groups & $\mathrm{A}$ & $\mathrm{B}$ & $\mathrm{C}$ & $\mathrm{D}$ & $\mathrm{E}$ \\
\hline Concrete & 0.0015 & 0.0015 & 0.0015 & 0.0015 & 0.0015 \\
CMU & 0.0014 & 0.0014 & 0.0014 & 0.0014 & 0.0014 \\
Cut Stone & 0.0308 & 0.0312 & 0.0312 & 0.0312 & 0.0312 \\
Structural Steel & 0.0014 & 0.0017 & 0.0014 & 0.0014 & 0.0014 \\
Wood & 0.0571 & 0.0682 & 0.0648 & 0.0648 & 0.0648 \\
Membrane/Waterproofing and sealants & 0.1941 & 0.1714 & 0.1783 & 0.1783 & 0.1783 \\
Flashing & 4.8529 & 4.0188 & 4.8529 & 4.8529 & 4.8529 \\
Plaster & 0.1125 & 0.1705 & 0.2124 & 0.1641 & 0.2689 \\
Aluminum & 0.1550 & 0.1414 & 0.1550 & 0.1550 & 0.1550 \\
Glass & 0.2271 & 0.2110 & 0.2221 & 0.2221 & 0.2221 \\
Paint & 0.2416 & 0.2037 & 0.2416 & 0.2416 & 0.2416 \\
Terrazzo Flooring/Ceramic Tile/Face Brick & 0.0385 & 0.0356 & 0.0423 & 0.0423 & 0.0423 \\
Carpet & 1.0848 & 0.7860 & 0.9141 & 0.9141 & 0.9141 \\
Ceiling & 0.2071 & 0.1967 & 0.1967 & 0.1967 & 0.1967 \\
\hline
\end{tabular}




\section{Discussion}

Embodied energy calculations are complex and data intensive. Primary data is difficult to obtain and secondary data has issues of data quality. The results of this study are in alignment with previous studies (Ding, 2004; Langston, 2006; Jiao et al., 2012; Copiello, 2016), and demonstrate that predicting EE from cost data may be possible. If so, significant efforts to quantify, establish, and update EE data for construction materials can be circumvented saving significant amounts of time and money. Results also showed that applying the EE intensity of the whole construction sector may be misleading, as disaggregating total cost and using material group-specific EE intensities showed a dramatic increase in EE. One possible reason for this can be the difference between the energy intensities of construction materials and the construction sector. If the EE intensity of construction sector is applied to an aggregated construction sector, it may underestimate or overestimate EE of material groups having higher or lower EE intensities than the construction sector, respectively. For instance, while calculating embodied energy of structural steel and concrete, the industry sectors of iron, steel and ferroalloy manufacturing and ready-mix concrete manufacturing were considered, which have higher EE intensities than the construction sector as a whole. Because the calculation by cost disaggregation provides material specific results, using disaggregated costs will also improve the specificity of EE results.

The dependency of embodied energy on cost was investigated by calculating the coefficient of correlation between embodied energy and cost and further performing regression analysis. When EE and cost per unit of mass were compared, the EE-cost correlation was very strong for all five buildings (see Figure 3). At the total cost and EE of material level, the correlation was very strong for buildings " $\mathrm{A}$ " and " $\mathrm{D}$ ", strong for building " $\mathrm{C}$ ", and moderate strong for buildings "B" and "E" (see Figure 2). The difference between $r^{2}$ values across the five buildings under study could be explained by the type of structure and the varying material proportions in the buildings. For instance, Building " $\mathrm{C}$ " is a green building with light-reflecting roof and a large water cistern churning in the basement, which profoundly influences EE. Building " $\mathrm{B}$ " has an auditorium with a green roof on top and a basement level, which makes a significant difference to EE. Building " $\mathrm{D}$ " has an enormous steel structure to harvest rainwater, which increases its EE as well as affect EE-cost correlation. Presence of such additional systems may have influenced the correlation between EE and cost. Varying cost to energy ratios for different materials could be another reason for the difference in $r^{2}$ values.
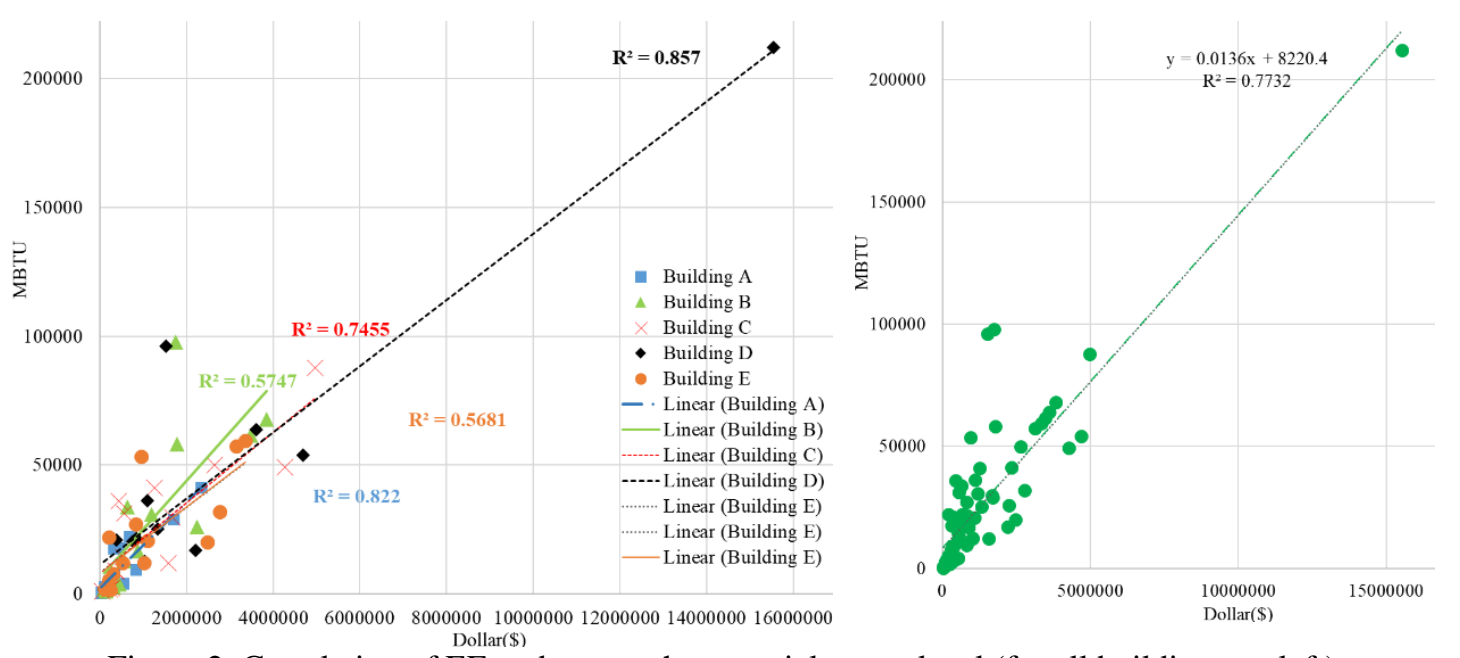

Figure 2. Correlation of EE and cost at the material group level (for all buildings on left) 


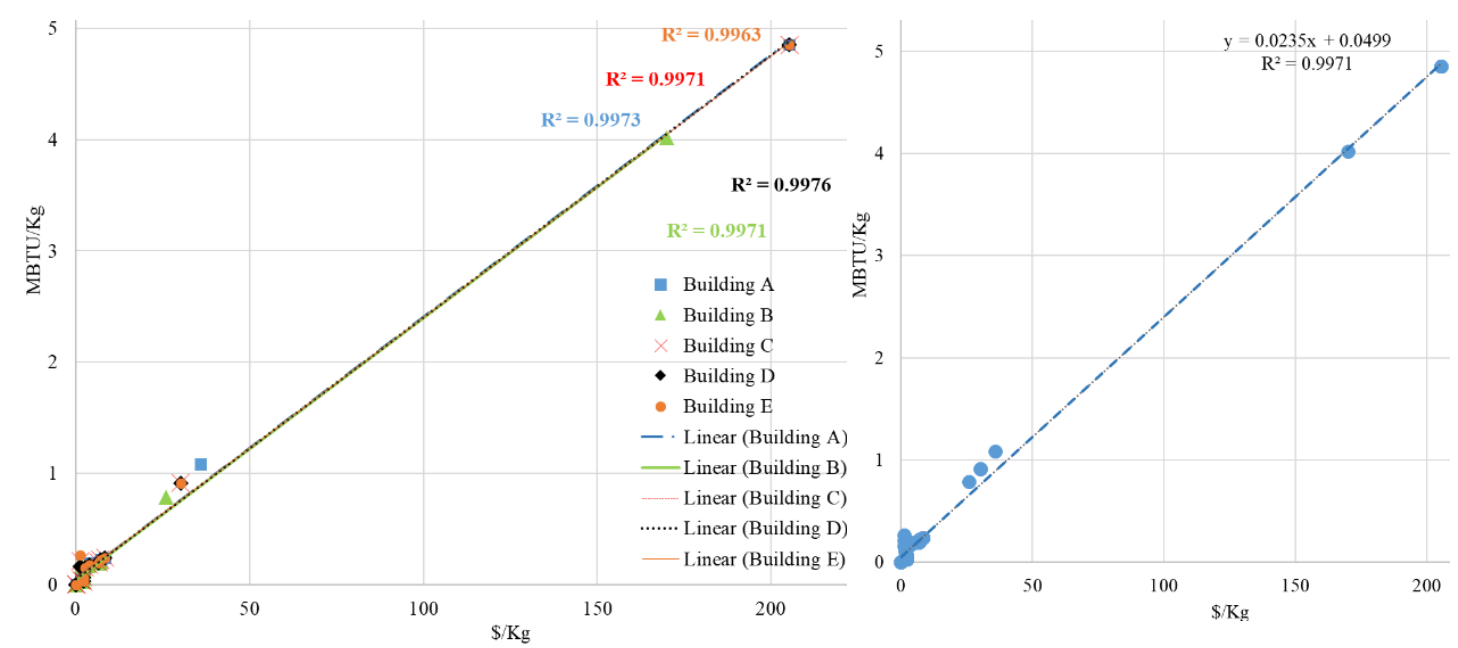

Figure 3. Correlation of EE and cost per unit of mass of materials (for all buildings on left)

\section{Conclusions}

This study applied input-output-based hybrid (IOH) data to calculate EE of five higher educational buildings at Texas A\&M University and testing the correlation between EE and cost. The aim was to examine any correlation between EE and cost of a building at the material group as well as the entire building levels. We also wanted to investigate if embodied energy could be estimated by the cost of building materials installed in the five buildings under study. The results support a strong to very strong and positive correlation between EE and cost of building materials at both the total cost and cost per unit of mass levels. As the correlation was strong, simple linear regression analysis was performed. Low $p$-value and Significance of $F$ confirmed the correlation, which increased the estimating confidence in the slope coefficient or gradient $(m)$ of the regression line.

As embodied energy calculation by disaggregating a building into material groups is very resource consuming, the need of disaggregation was investigated by comparing results at the material and building levels. As the results demonstrate a significant increase in EE values, the need for disaggregation is justified to enhance completeness, accuracy and specificity of embodied energy calculation. In order to better predict embodied energy from cost, more commonly used materials should be included. Also, including systems such as mechanical, electrical and plumbing should be considered to further investigate the energy-cost relationship. With an increasing focus on designing and constructing energy efficient buildings, the relationship between EE and cost could be more significant. Such a relationship could also help eliminate a common misconception that reducing energy and environmental impacts may adversely influence a building's cost. If analyzed over a building's life cycle, reducing building costs could mean decreasing the EE and environmental footprint of the building. Such a relationship between energy and cost could also provide incentives for owners and designers to prefer energy efficient alternatives due to possible cost savings.

\section{References}

Balouktsi, M., \& Lützkendorf, T. (2016). Energy Efficiency of Buildings: The Aspect of Embodied Energy. Energy Technology, 4(1), 31-43. 
Carter, A. J., Peet, N. J., \& Baines, J. T. (1981). Direct and Indirect Energy Requirements of the New Zealand Economy: An Energy Analysis of the 1971-72 Inter-industry Survey. Technical Report \# NZERDC-P-55, New Zealand Energy Research and Development Committee, Auckland, New Zealand.

Chan, Y. H. (2003). Biostatistics 104: correlational analysis. Singapore Medical Journal, 44(12), 614619.

Copiello, S. (2016). Economic implications of the energy issue: Evidence for a positive non-linear relation between embodied energy and construction cost. Energy and Buildings, 123, 59-70.

Costanza, R. (1980). Embodied energy and economic valuation. Science, 210(4475), 1219-1224.

Crawford, R. H. (2004). Using input-output data in life cycle inventory analysis (Ph.D. Dissertation). School of Architecture and Building, Deakin University, Victoria, Australia. URL: http://hdl.handle.net/10536/DRO/DU:30023201.

Ding, G. K. C. (2004). The development of a multi-criteria approach for the measurement of sustainable performance for built projects and facilities (Ph.D. Dissertation). University of Technology, Sydney, Australia. URL: http://hdl.handle.net/10453/20191.

Dixit, M. K. (2017a). Life cycle embodied energy analysis of residential buildings: A review of literature to investigate embodied energy parameters. Renewable and Sustainable Energy Reviews, $79,390-413$.

Dixit, M. K. (2017b). Embodied energy and cost of building materials: correlation analysis. Building Research \& Information, 45(5), 508-523.

Dixit, M. K. (2018). Life Cycle Recurrent Embodied Energy Calculation of Buildings: A Review. Journal of Cleaner Production, 209, 731-754.

Dixit, M. K., \& Singh, S. (2018). Embodied energy analysis of higher education buildings using an input-output-based hybrid method. Energy and Buildings, 161, 41-54.

Dixit, M. K., Culp, C. H., \& Fernandez-Solis, J. L. (2014). Calculating primary energy and carbon emission factors for the United States' energy sectors. RSC Advances, 4(97), 54200-54216.

Dixit, M. K., Culp, C. H., \& Fernandez-Solis, J. L. (2015). Embodied energy of construction materials: Integrating human and capital energy into an IO-based hybrid model. Environmental Science \& Technology, 49(3), 1936-1945.

Hammond, G., Jones, C., Lowrie, F., \& Tse, P. (2011). Embodied carbon: the inventory of carbon and energy (ICE). The University of Bath and Building Services Research and Information Association (BSRIA), Bracknell, Berkshire, U.K. URL: https://greenbuildingencyclopaedia.uk/wpcontent/uploads/2014/07/Full-BSRIA-ICE-guide.pdf.

Jiao, Y., Lloyd, C., \& Wakes, S. (2012). The relationship between total embodied energy and cost of commercial buildings. Energy and Buildings, 52, 20-27. 
Langston, Y. L. (2006). Embodied energy modeling of individual buildings in Melbourne, the inherent energy-cost relationship (Ph.D. Dissertation). School of Architecture and Building, Deakin University, Victoria, Australia. URL: http://hdl.handle.net/10536/DRO/DU:30026975.

Ristimäki, M., Säynäjoki, A., Heinonen, J., \& Junnila, S. (2013). Combining life cycle costing and life cycle assessment for an analysis of a new residential district energy system design. Energy, 63, 168179.

Stephan, A., \& Stephan, L. (2016). Life cycle energy and cost analysis of embodied, operational and user-transport energy reduction measures for residential buildings. Applied Energy, 161, 445-464.

Taylor, R. (1990). Interpretation of the correlation coefficient: a basic review. Journal of Diagnostic Medical Sonography, 6(1), 35-39.

Treloar, G. J. (1998). A comprehensive embodied energy analysis framework (Ph.D. Dissertation). Faculty of Science and Technology, Deakin University, Victoria, Australia. URL:

http://hdl.handle.net/10536/DRO/DU:30023444.

Vukotic, L., Fenner, R. A., \& Symons, K. (2010, September). Assessing embodied energy of building structural elements. Proceedings of the Institution of Civil Engineers - Engineering Sustainability. 163(3), 147-158. 